\title{
CORRIGENDUM
}

\section{Mars: new insights and unresolved questions - Corrigendum}

Hitesh G. Changela, Elias Chatzitheodoridis, Andre Antunes, David Beaty, Kristian Bouw, John C. Bridges, Klara Anna Capova, Charles S. Cockell, Catharine A. Conley, Ekaterina Dadachova, Tiffany D. Dallas, Stefaan de Mey, Chuanfei Dong, Alex Ellery, Martin Ferus, Bernard Foing, Xiaohui Fu, Kazuhisa Fujita, Yangting Lin, Sohan Jheeta, Leon J. Hicks, Sen Hu, Akos Kereszturi, Alexandros Krassakis, Yang Liu, Juergen Oberst, Joe Michalski, P. M. Ranjith, Teresa Rinaldi, David Rothery, Hector A. Stavrakakis, Laura Selbmann, Rishitosh K. Sinha, Alian Wang, Ken Williford, Zoltan Vaci, Jorge L. Vago, Michael Waltemathe and John E. Hallsworth

(First published online 10 January 2022)

DOI: https://doi.org/10.1017/S1473550421000276 Published online by Cambridge University Press: 01 December 2021

The authors apologise that upon publication of this article the author Yangting Lin's name was incorrectly spelled. Within the original article the authors name was spelled Yangtin Lin.

Additionally, the reference for Hu X, Oberst J and Willner K (2020) was not included in the article. The online version of this article has been updated.

\section{Reference}

Changela HG et al. (2021). Mars: new insights and unresolved questions. International Journal of Astrobiology 1-33. https://doi. org/10.1017/S1473550421000276 